\title{
Epidemiology of echinococcosis in Iran: a systematic review and meta-analysis
}

\author{
Shima Mahmoudi ${ }^{1,2}$, Setareh Mamishi ${ }^{1}$, Maryam Banar ${ }^{1}$, Babak Pourakbari ${ }^{1}$ and Hossein Keshavarz ${ }^{2,3^{*}}$
}

\begin{abstract}
Background: Echinococcosis is a zoonotic disease caused by the larval stages of taeniid cestodes of the genus Echinococcus. The two major types of infection in humans are cystic echinococcosis (CE) or hydatidosis and alveolar echinococcosis (AE). It is endemic in some parts of the world, such as the Middle East, with Iran being a part of it. This systematic review and meta-analysis were conducted to determine the prevalence of CE and AE echinococcosis and their epidemiological and clinical aspects in Iran.

Methods: Electronic databases, including MEDLINE (via PubMed), SCOPUS, Web of Science, SID and Mag Iran (two Persian scientific search engines) were searched from 1 January 1990 to 8 August 2017. The prevalence of CE and AE echinococcosis was estimated using the random effects meta-analysis. Heterogeneity was evaluated by subgroup analysis. Data were analyzed by STATA version 12 .

Results: Of the 2051 records identified in the mentioned electronic databases, Seventy-eight articles met our eligibility criteria, with a total of 214124individuals. The meta-analysis was performed on only 37 out of 78 included studies. The pooled prevalence of CE and AE in Iran was 5\% [95\% confidence interval )Cl(: 3-6\%] and 2\% [95\% Cl: 0$5 \%]$, respectively. Subgroup meta-analysis revealed that the prevalence of CE was significantly higher in North [9\%, 95\% Cl: 4-18\%] and West of Iran [6\%, 95\% Cl: 3-11\%], patients younger than 40 years of age [7\%, 95\% Cl: 4-12\%], villagers and nomads [6\%,95\% Cl: 2-12\%], and studies that used the combination of serological, clinical, and imaging diagnostic methods [7\%, 95\% Cl: 5-9\%]. There were no significant differences between the prevalence of CE among low and high-quality studies. Housewives were the most affected group by hydatidosis $(n=24 / 77,31 \%)$, followed by illiterate people ( $n=11 / 77,14 \%)$ and farmers ( $n=9 / 77,12 \%)$. Liver [55\%, 95\% Cl: 46-65\%] and lung [28\%, $95 \% \mathrm{Cl}, 22-35 \%]$ were the most common sites of cyst formation.
\end{abstract}

Conclusions: Given to the importance of echinococcosis on human health and domestic animals industry, it is necessary to implement monitoring and control measures in this regard.

Keywords: Cystic echinococcosis, Alveolar echinococcosis, Prevalence, Iran

\section{Background}

Echinococcosis is an important chronic zoonotic disease in many parts of the world including Iran [1-3], which caused by the larval stages of the parasites belonging to the genus Echinococcus [4,5]. According to the estimation of World Health Organization (WHO), more than one million people are affected by echinococcosis

\footnotetext{
* Correspondence: hkeshavarz@tums.ac.ir; dr.hkeshavarz@gmail.com ${ }^{2}$ Center for Research of Endemic Parasites of Iran (CREPI), Tehran University of Medical Sciences, Tehran, Iran

${ }^{3}$ Department of Medical Parasitology and Mycology, School of Public Heath, Tehran University of Medical Sciences, Poursina st, P.O. Box 14155-6446, Tehran, Iran

Full list of author information is available at the end of the article
}

globally each year and in 2015, resulted in 19300 death cases around the world. Every year, the cost of treating patients with echinococcosis as well as damage to the livestock industry is about 3 billion dollars [6].

Humans are accidental intermediate hosts and acquire the infection via direct contact with infected final hosts (i.e. carnivores such as dogs, foxes, coyotes, and wolves) or via ingestion of parasite's embryonated eggs in contaminated food, water, or soil $[1,6,7]$. The two major types of infection in humans are cystic echinococcosis (CE) or hydatidosis (caused by the species $E$. granulosus) and alveolar echinococcosis (AE) (caused by the species E. multilocularis) that have serious health and economic

(C) The Author(s). 2019 Open Access This article is distributed under the terms of the Creative Commons Attribution 4.0 International License (http://creativecommons.org/licenses/by/4.0/), which permits unrestricted use, distribution, and 
implications and vast geographical distribution $[5,6,8]$. $\mathrm{CE}$ is characterized by the formation of one or more cystic lesions in the liver, lung, kidney or other body organs and $\mathrm{AE}$ is defined as the development of a tumorlike lesion that usually occurs in the liver $[4,6]$.

According to the previous systematic review and meta-analysis study conducted by Shafiei et al., in 2016 [2], the estimated prevalence of CE in Iran was $5 \%$ [95\% CI: 4-7\%]. The disease was most frequent among women and older patients, and the highest prevalence of $C E$ was observed in the southwest and south of Iran. In another systematic review and meta-analysis done by Khalkhali et al., in 2017 [9], the prevalence of human hydatidosis was $4.2 \%$ [95\% CI: 3-5.5\%]. Most cases were women, and the disease was most prevalent in rural regions and southern Iran.

Studies demonstrated that the most prevalent genotypes of E. granulosus in Iran are G1 (92.75\%) and G6 $(4.53 \%)$ in sheep, cattle, camels, goats, and buffaloes [10]. G1 is also the most frequent genotype in human CE $[10,11]$.

Every year a lot of body organs (especially livers and lungs) are damaged due to the infection with this parasite and imposes considerable costs on the health care system [12]. The expense of human CE in Iran was estimated at US\$93.39 million [95\% CI US\$6.1-222.7 million]. In addition, the cost of surgery for each human case of $\mathrm{CE}$ was estimated at US $\$ 1,539$ [13].

With regard to the medical and economic importance of this disease, it is essential to implement strong monitoring programs in order to assess the burden of disease and the progress made in control programs [6]. We accomplished a systematic review and meta-analysis to determine the prevalence of $\mathrm{CE}$ and $\mathrm{AE}$ echinococcosis and their epidemiological and clinical aspects in Iran.

\section{Methods}

Search method and selection criteria

Three English electronic databases (MEDLINE (via PubMed), SCOPUS, and Web of Science) and two Persian electronic databases (Magiran and Scientific Information Database (SID)) were searched systematically from 1 January 1990 to 8 August 2017. Publication searches were performed by various combinations of the following terms: "Hydatidosis" or "Echinococcosis" or "Hydatid cyst" or "Echinococcus granulosus" or "Echinococcus multilocularis" or "Alveolar hydatid cyst" or "liver and alveolar hydatid cyst" or "hepatic alveolar hydatid cyst" or "Alveolar echinococcosis" or "Cystic echinococcosis" AND "Human" AND "Iran". The reference lists of selected articles also were screened manually and appropriate articles were included. Abstracts of papers published in congresses were not reviewed because they did not have enough details for quality assessment. Dissertations and thesis were not included. The study was conducted according to the guidelines of PRISMA (the preferred reporting items for systematic reviews and metaanalyses) [14]. Titles and abstracts of all articles were screened by one reviewer, and eligibility of the screened articles was assessed by two independent investigators using the following criteria.

\section{Inclusion criteria}

Case definition A patient was diagnosed as echinococcosis-infected case if his blood sample was positive for antiechinococcus antibodies (diagnosed by enzyme-linked immunosorbent assay (ELISA), or indirect hemagglutination antibody test (IHA), or indirect fluorescent antibody test (IFA), or counterimmunoelectrophoresis (CIE)) or his clinical characteristics (diagnosed by computed tomography (CT) scan, magnetic resonance imaging (MRI), chest-X ray, ultrasonography, bronchoscopy, or radiology) or pathological properties were indicative of echinococcosis [15].

Articles were included whether they have recognized echinococcosis based on clinical symptoms /imaging or radiographic characteristics or identified the disease using serological tests or pathological examinations. Only articles that reported human echinococcosis were included. Iranian papers in each language of Persian or English were enrolled.

\section{Exclusion criteria}

Investigations with not-relevant topics, review and case report articles were excluded. Reports from other countries were disqualified.

\section{Data extraction}

Two independent reviewers read the included articles in full text and extracted the following data: first author's name, year of study, location of study, sample size, gender of patients, the most affected age group, number of patients diagnosed with echinococcosis, types of echinococcosis (i.e. $\mathrm{CE}$ or $\mathrm{AE}$ ), diagnostic methods used, and the most common infected group. Any disagreement between the two reviewers was resolved by consensus.

\section{Quality assessment}

The quality of the included articles was assessed using the Joanna Briggs Institute (JBI) critical appraisal checklist for studies reporting prevalence data [16]. This action was performed by two independent reviewers and any dispute was resolved through discussion. 


\section{Meta-analysis}

Random-effects model was used to pool the estimations; and standard methods recommended for meta-analyses of prevalence were employed. Outcomes were the total prevalence of $\mathrm{CE}$ and $\mathrm{AE}$ in Iran and the prevalence of $\mathrm{CE}$ in different sites of body. Results of the meta-analysis were shown as a forest plot diagram, which represents the estimated prevalence and their relevant 95\% confidence interval (CI). The Cochran's heterogeneity statistic ( -test) and ${ }^{2}$ statistic were used to examine the heterogeneity of studies. The $I^{2}$ values of $25 \%, 50 \%$, and $75 \%$ were considered as low, medium, and high heterogeneity, respectively.

Subgroup meta-analysis was utilized to compare the prevalence of $\mathrm{CE}$ on the basis of geographic distribution of studies (North, Center, West, and East of Iran), patients' age (age $<4$ o years vs. age $\geq 40$ years), quality score of the studies (the study score $<5$ (low quality) vs. the study score $\geq 5$ (high quality)), diagnostic lab methods used in the studies (serological vs. serological and clinical methods), and place of residence of the patients (urban, urban and rural, rural and nomad). The $\mathrm{Q}$ and $I^{2}$ statistics values were calculated for each subgroup to determine the effective factors on the prevalence of $\mathrm{CE}$ and heterogeneity of the studies. Publication bias were evaluated by Egger's regression test [17].

This meta-analysis procedure was accomplished using STATA software (Release 12. statistical software. College Station, Texas: STATA Corp LP).

\section{Study area}

Iran consists of a land area of over 1.6 million square kilometers. It is bounded by Iraq and Turkey in the west, Afghanistan and Pakistan in the east, the Persian Gulf and Oman Sea in the south, as well as Caspian Sea, Azerbaijan, Armenia and Turkmenistan in the north. The country generally features three climatic zones, including: arid and semi-arid climate of the interior and far south, mountainous climate, and Caspian climate. In the year 2012, Iran was divided into 31 provinces [18] and according to the last Population and Housing

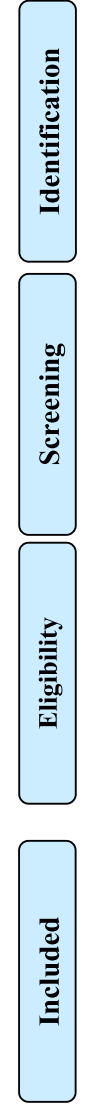

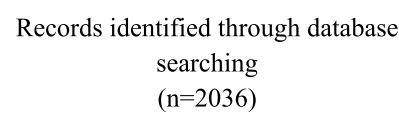

Additional records identified

through other sources $(\mathrm{n}=15)$
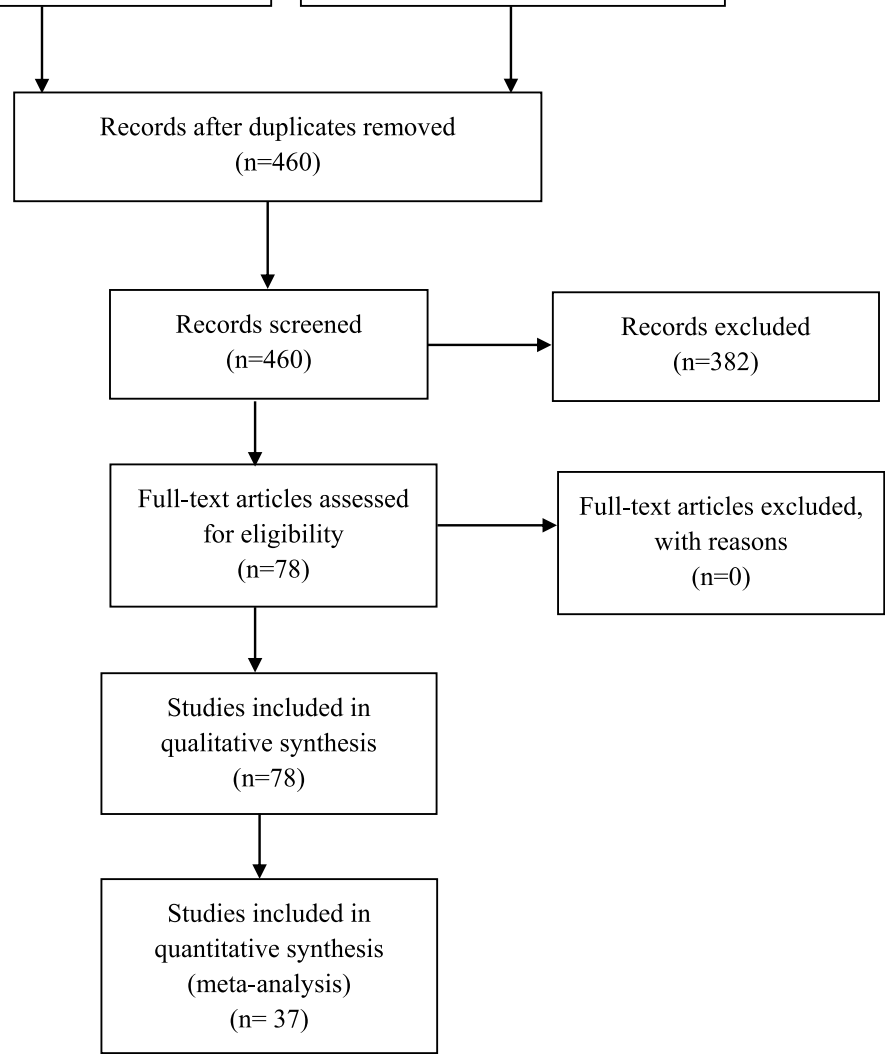

Fig. 1 Summary of the literature search and study selection 


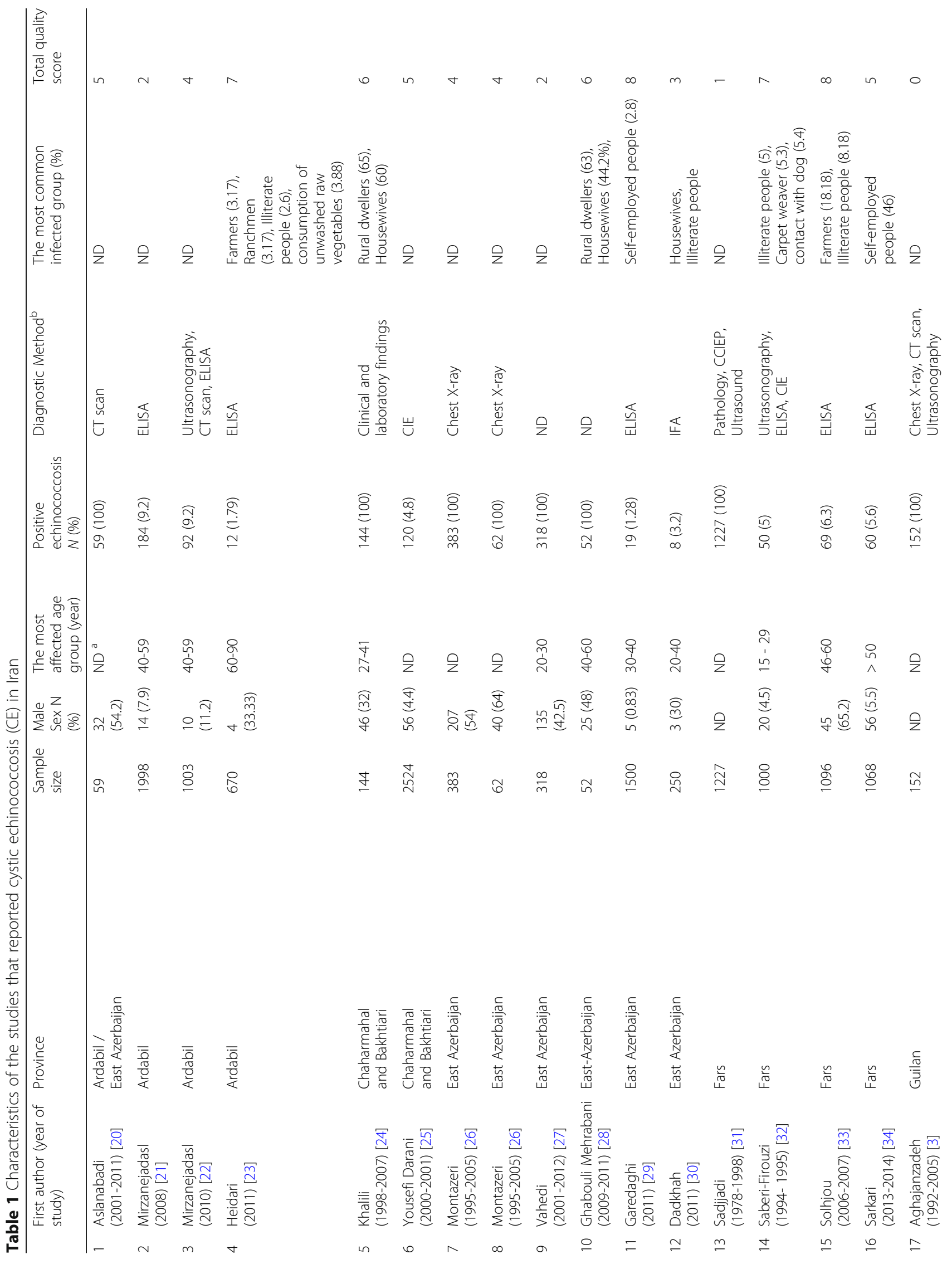




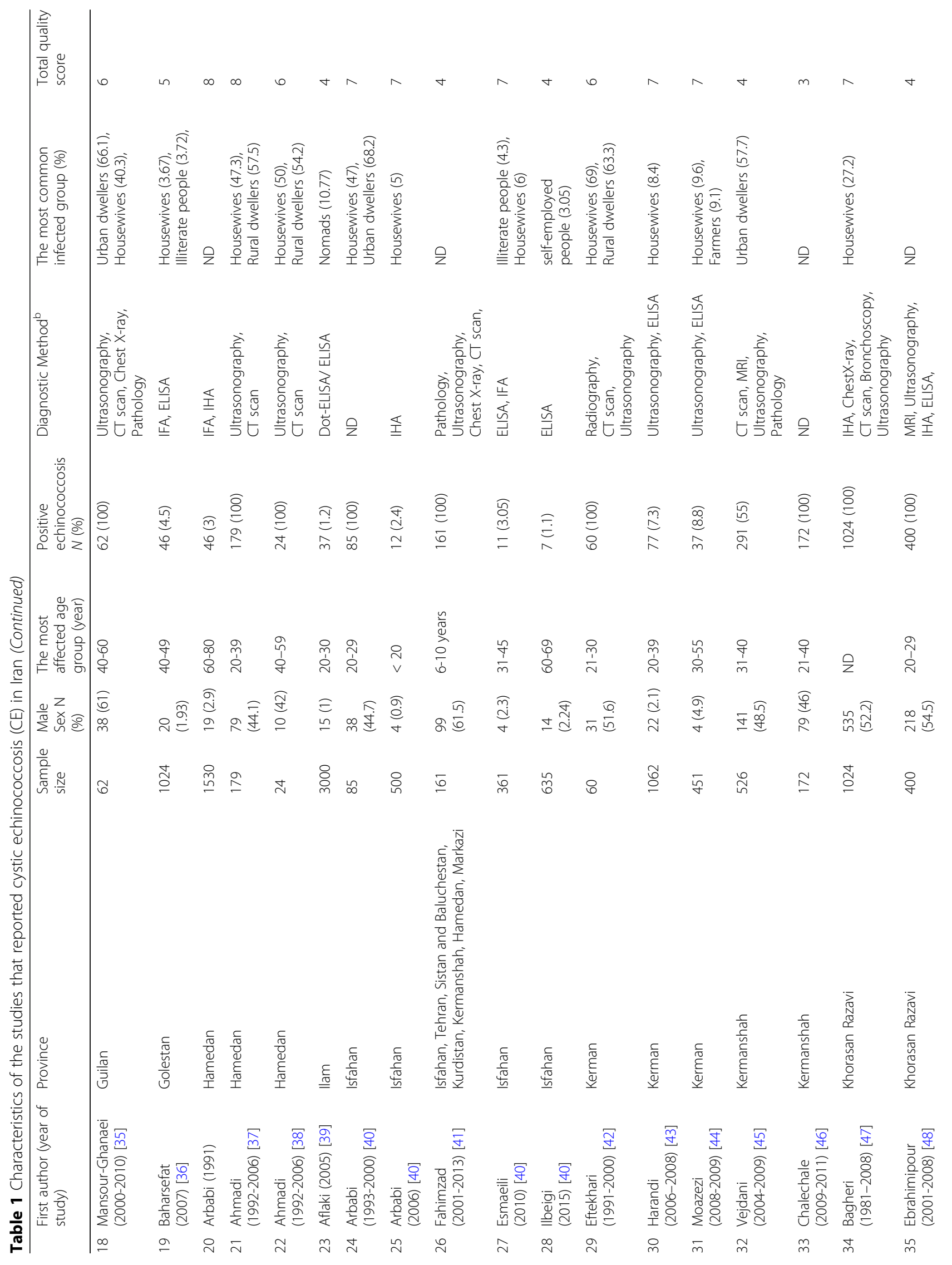




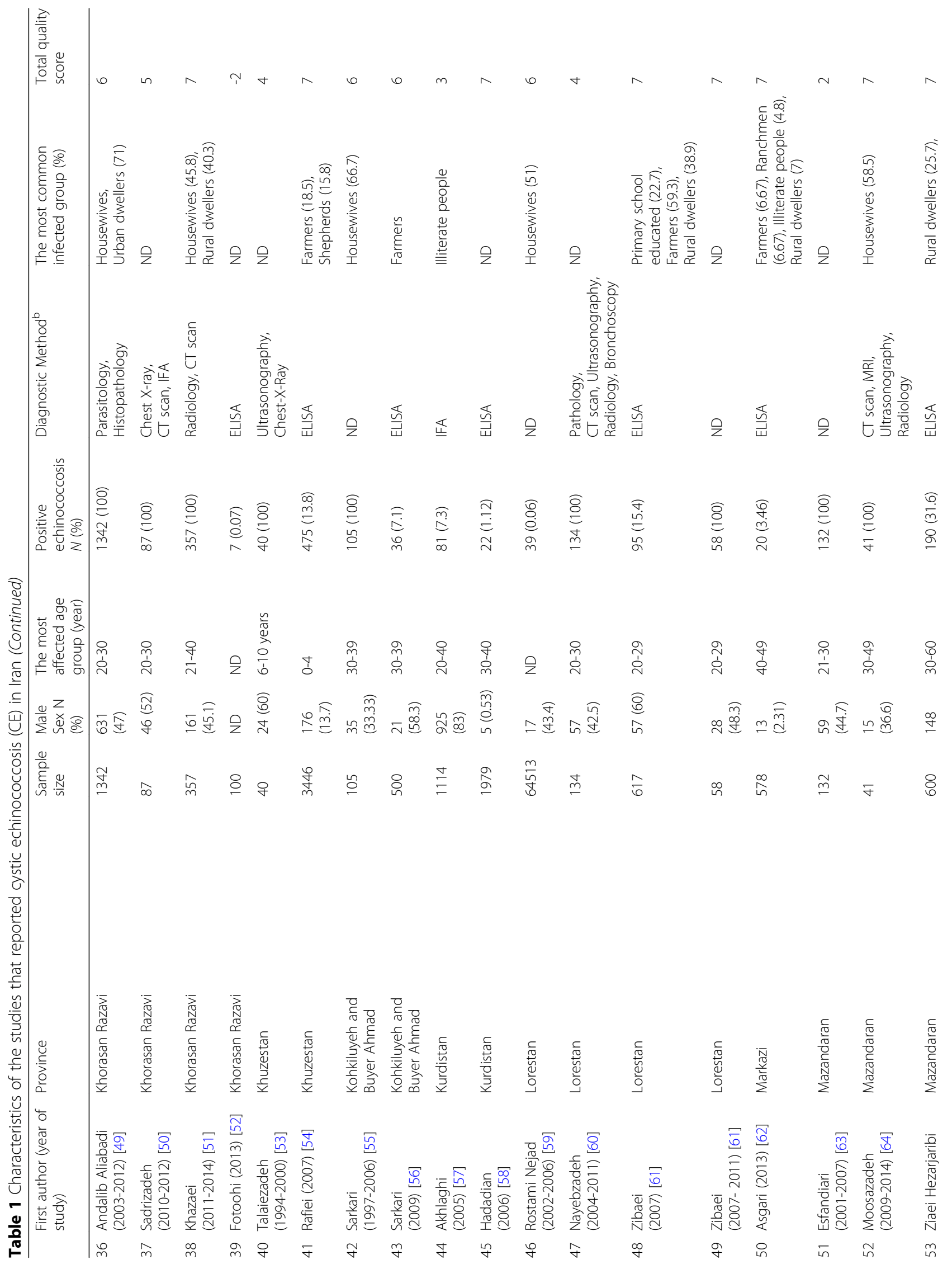




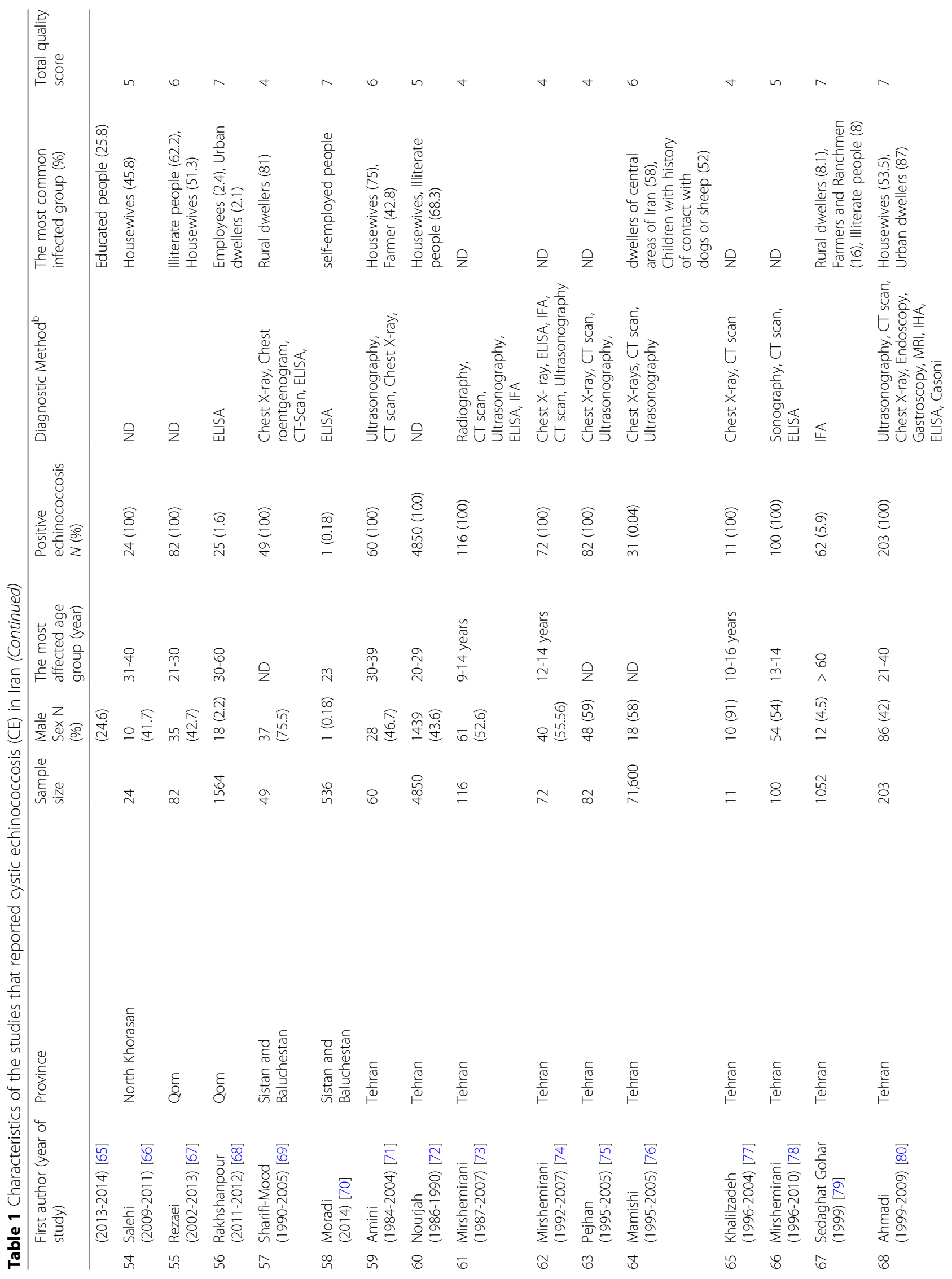


Mahmoudi et al. BMC Infectious Diseases

(2019) 19:929

Page 8 of 19

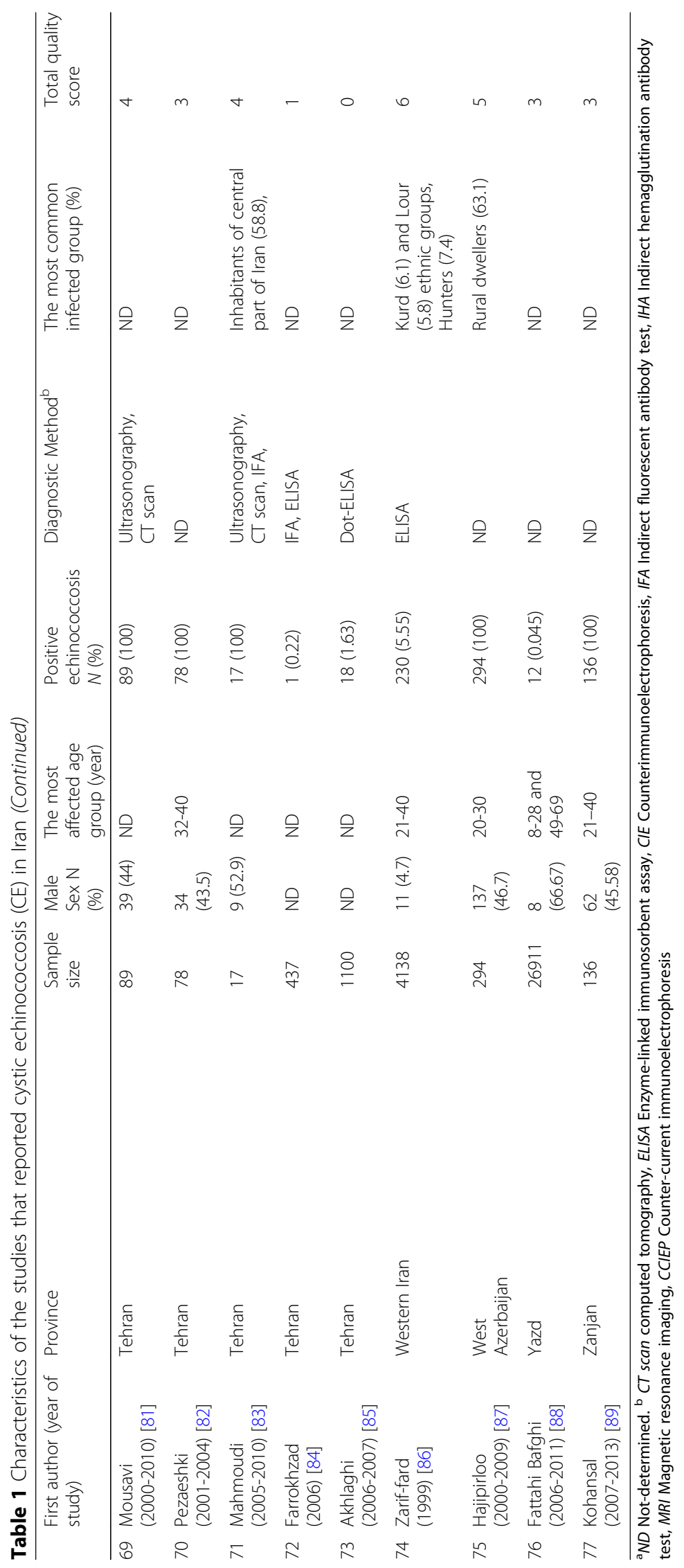


Table 2 Characteristics of the studies that reported alveolar echinococcosis (AE) in Iran

\begin{tabular}{|c|c|c|c|c|c|c|c|c|c|}
\hline & $\begin{array}{l}\text { First author (year } \\
\text { of study) }\end{array}$ & Province & $\begin{array}{l}\text { Sample } \\
\text { size }\end{array}$ & $\begin{array}{l}\text { Male Sex } \\
N(\%)\end{array}$ & $\begin{array}{l}\text { The most affected } \\
\text { age group (year) }\end{array}$ & $\begin{array}{l}\text { Positive } \\
\text { N (\%) }\end{array}$ & Diagnostic Method $^{\mathrm{b}}$ & $\begin{array}{l}\text { The most common } \\
\text { infected group (\%) }\end{array}$ & $\begin{array}{l}\text { Total } \\
\text { score }\end{array}$ \\
\hline 1 & $\begin{array}{l}\text { Mirshemirani } \\
(1987-2007) \text { [73] }\end{array}$ & Tehran & 116 & $N D^{a}$ & ND & $3(2.6)$ & $\begin{array}{l}\text { Radiography, CT scan, } \\
\text { Sonography, ELISA, IFA }\end{array}$ & ND & 4 \\
\hline 2 & $\begin{array}{l}\text { Mirshemirani } \\
(1992-2007) \text { [74] }\end{array}$ & Tehran & 72 & ND & ND & $1(2)$ & $\begin{array}{l}\text { Chest X-ray, ELISA, IFA, CT } \\
\text { scan, Ultrasonography }\end{array}$ & ND & 4 \\
\hline 3 & $\begin{array}{l}\text { Maddah (1997- } \\
\text { 2012) [90] }\end{array}$ & $\begin{array}{l}\text { Khorasan } \\
\text { Razavi }\end{array}$ & 18 & $4(21)$ & ND & $18(100)$ & Ultrasonography, CT scan & ND & 4 \\
\hline
\end{tabular}

${ }^{a} N D$ Not-determined. ${ }^{b} C T$ scan Computed tomography, MRI Magnetic resonance imaging, ELISA Enzyme-linked immunosorbent assay, IFA Indirect fluorescent antibody test

Census taken in 2016; the total population of the country was 79926270 persons (comprising 50.66\% male and $49.34 \%$ female), which 59146847 persons (74\%) were urban dwellers and the 20730625 persons (26\%) were settled in rural areas [19].

\section{Results}

Of the 2051 records identified in the mentioned electronic databases and through articles' reference lists (Fig. 1), 78 articles met inclusion criteria and enrolled into the systematic review. Only 37 articles that reported the prevalence of $\mathrm{CE}$ and $\mathrm{AE}$ in their understudy populations were included in the meta-analysis. The characteristics of the included studies are summarized in Tables 1 and 2.

In overall, studies had a wide geographical distribution and were carried out in 25 different provinces of Iran. Most studies (15 articles) were from Tehran $(n=79867)$ [71-85], seven were from Khorasan Razavi $(n=3328)$ [47-52, 90], six were from East Azerbaijan $(n=2565)$ [26-30], four each were from Isfahan $(n=1581)[40,91,92]$ and Lorestan (65322) [59-61], three each were from Mazandaran ( $n=773)$ [63-65], Kerman $(n=1573)$ [42-44], Ardabil $(n=3671)$ [21-23], and Hamedan $(n=1733)$ [37, 38, 93], two each were from Chaharmahal and

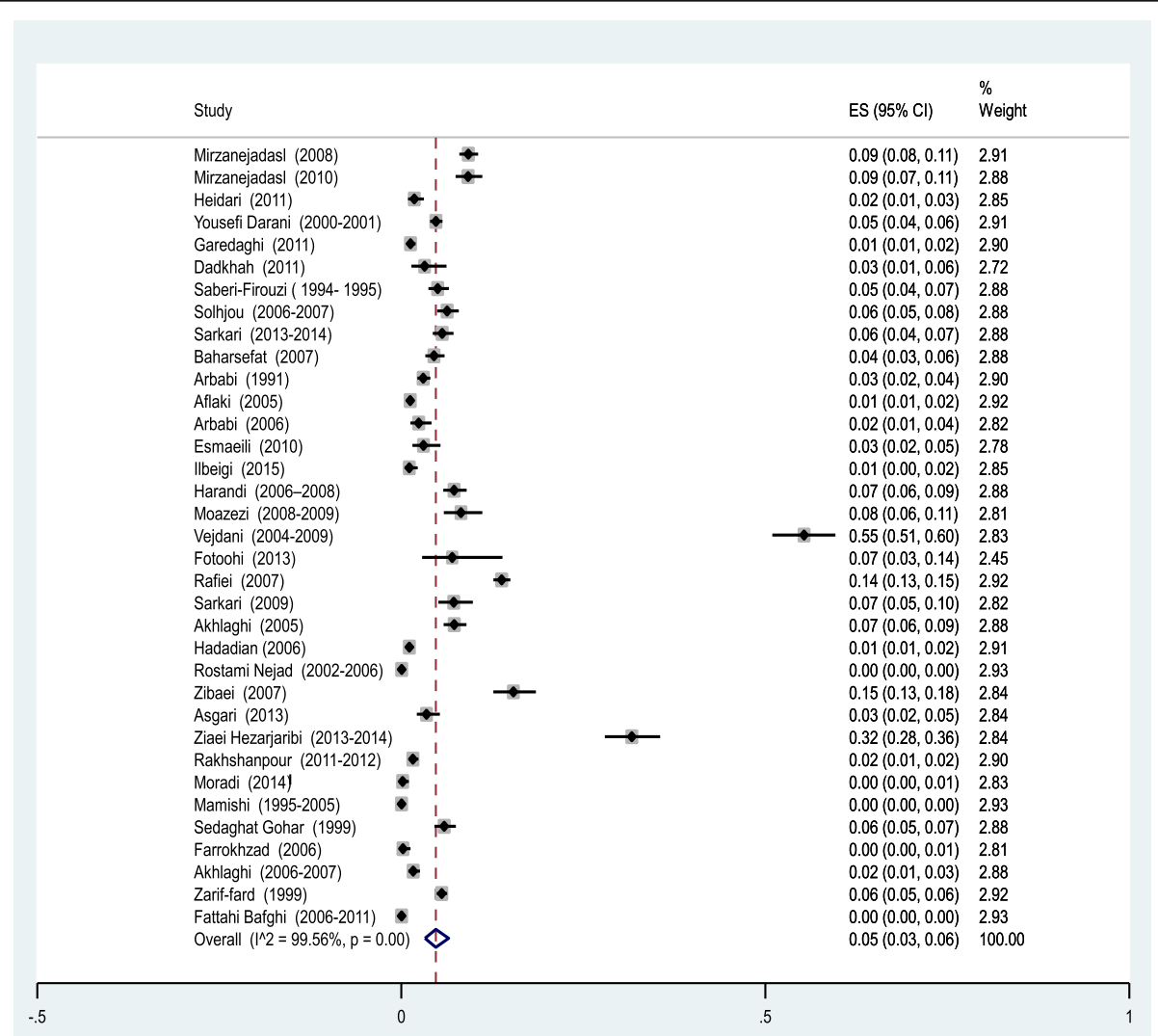

Fig. 2 Forest plot diagram of the total prevalence of cystic echinococcosis (CE) in Iran. The middle point of each line indicates the prevalence rate and the length of line indicates $95 \%$ confidence interval of each study. The opened diamond is representatives of the overall prevalence of the studies 
Bakhtiari $(n=2668)$ [24, 25], Fars $(n=4391)$ [31-34], Guilan $(214)$ [3, 35], Kermanshah $(n=698)$ [45, 46], Khuzestan $(n=3486)$ [53, 54], Kohkiluyeh and Buyer Ahmad $(n=605)$ [55, 56], Kurdistan $(n=3093)$ [57, 58], Qom $(n=1646)[67,68]$, Sistan and Baluchestan $(n=585)$ $[69,70]$, one each were from Golestan $(n=1024)$ [36], Ilam $(n=3000)$ [39], Markazi $(n=578)$ [62], North Khorasan $(n=$ 24) [66], West Azerbaijan $(n=294)$ [87], Yazd $(n=26911)$ [88], and Zanjan $(n=136)$ [89]. One study was performed in both Ardabil and East Azerbaijan $(n=59)$ [20], one study reported the number of hydatidosis infected patients admitted to eight major referral hospitals in Isfahan, Tehran, Sistan and Baluchestan, Kurdistan, Kermanshah, Hamedan, and Markazi $(n=161)$ [41], and finally, one study examined the serum samples of healthy volunteers from 8 different western provinces of Iran including Ardabil, East Azerbaijan, West Azerbaijan, Ilam, Kurdistan, Hamedan, and Lorestan $(n=4138)$ [86](Tables 1 and 2).

Among the 78 included studies, 75 studies reported only CE-infected individuals, 1 study reported only AEinfected patients [90], and two studies reported both $\mathrm{AE}$ and CE-infected cases [73, 74]. With regard to the few numbers of AE studies in Iran, only three studies were included in the systematic review, and two of them [73, 74] were assessed in the meta-analysis.

According to the results of the meta-analysis, the pooled prevalence of $\mathrm{CE}$ in Iran was estimated at 5\% [95\% CI: 3-6\%] (Fig. 2). In most studies (31 out of 77 studies, 40\%), CE-infected cases were in the age group of 20-40 years. Housewives were the most affected group by hydatidosis $(n=24 / 77,31 \%)$, followed by illiterate people $(n=11 / 77,14 \%)$ and farmers $(n=9 / 77,12 \%)$. In children, boys were more infected than girls $(n=315 / 548$, $57.5 \%)$. Serological techniques $(n=27 / 77,35 \%)$ were the most utilized method for diagnosis of $\mathrm{CE}$, followed by clinical and radiographic methods $(n=21 / 77,27 \%)$, and the combination of methods (i.e. serological, clinical and radiographic methods) ( $n=14 / 77,18 \%)$ (Table 1$)$.

Results of meta-analysis demonstrated a pooled prevalence of $(2 \%, 95 \%$ CI: $0-5 \%)$ for $\mathrm{AE}$ in Iran (Fig. 3). In overall, a total of 22 cases of AE were reported in 3 included studies. Two studies were conducted on children from pediatric hospitals of Tehran $[73,74]$, but they did not mention the exact age range and gender of AE patients. The other study was performed on AE patients from Khorasan Razavi province (North-east of Iran), and most of them were women with a mean age of $46.11 \pm 15.14$ years. Clinical and imaging methods (i.e. ultrasonography, CT scan, and MRI) were the most used diagnostic methods for AE (Table 2).

Different sites of hydatid cyst formation are shown in Table 3 and the pooled prevalence of hydatid cysts in different parts of the body are listed in Table 4. According to the results, liver [55\%, 95\% CI: 46-65\%] and lung [28\%, 95\% CI: $22-35 \%]$ were the most common sites of cyst formation (Figs. 4 and 5). The organs, in which the total number of cysts was less than 10 , were considered as unusual site of cyst formation, including: heart $(n=8$, $0.06 \%)$, spinal cord $(n=7,0.05 \%)$, bone $(n=6,0.04 \%)$, intestine $(n=6,0.04 \%)$, diaphragm $(n=5,0.03 \%)$, bladder

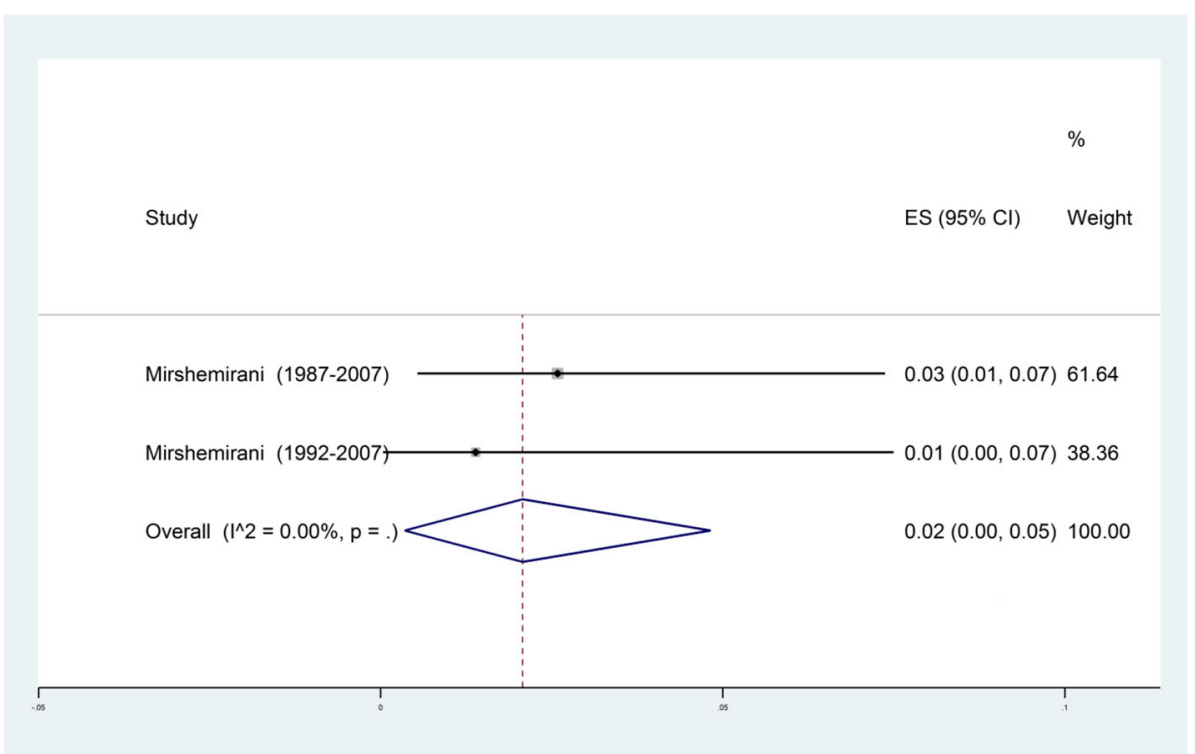

Fig. 3 Forest plot diagram of the total prevalence of alveolar echinococcosis (AE) in Iran. The middle point of each line indicates the prevalence rate and the length of line indicates $95 \%$ confidence interval of each study. The opened diamond is representatives of the overall prevalence of the studies 


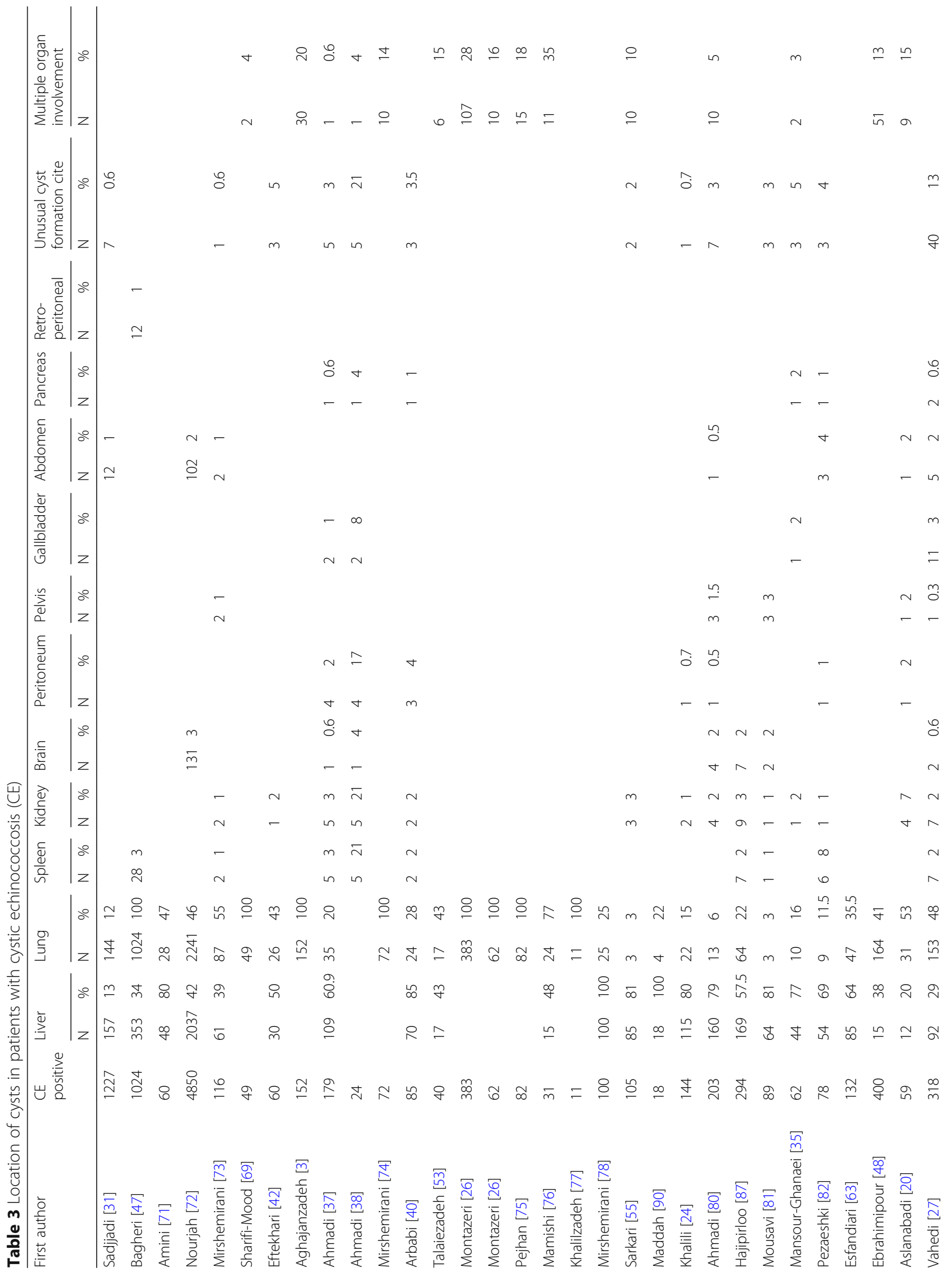




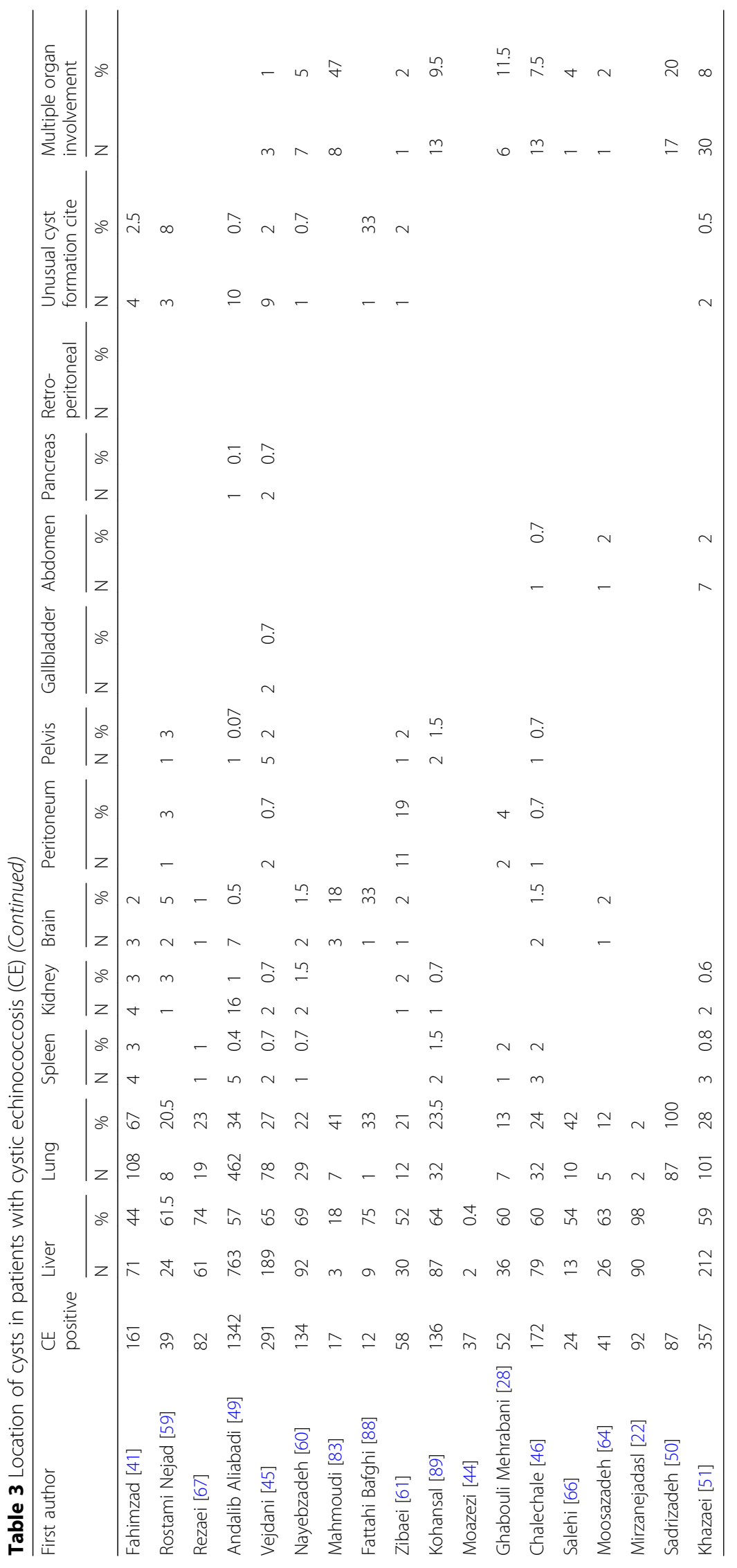


$(n=5,0.03 \%)$, ovary $(n=5,0.03 \%)$, pleura $(n=5,0.03 \%)$, bronchus $(n=5,0.03 \%)$, mediastinum $(n=5,0.03 \%)$, chest wall $(n=4,0.03 \%)$, mesentrium $(n=3,0.02 \%)$, adrenal glands $(n=3,0.02 \%)$, femur $(n=3,0.02 \%)$, uterus $(n=3$, $0.02 \%)$, esophagus $(n=2,0.01 \%)$, pericardium $(n=2$, $0.01 \%)$, facial sinuses $(n=2,0.01 \%)$, prostate $(n=2,0.01 \%)$, breast $(n=2,0.01 \%)$, inguinal canal $(n=2,0.01 \%)$, choledochus $(n=2,0.01 \%)$, colon $(n=2,0.01 \%)$, muscle $(n=2$, $0.01 \%)$, CNS $(n=2,0.01 \%)$, axillary cavity $(n=1,0.007 \%)$, skin $(n=1,0.007 \%)$, vertebrate $(n=1,0.007 \%)$, subcutaneous $(n=1,0.007 \%)$, neck $(n=1,0.007 \%)$, buttock $(n=1,0.007 \%)$, leg $(n=1,0.007 \%)$, bilious canal $(n=1$, $0.007 \%)$, supraclavicular area $(n=1,0.007 \%)$, and suprapubic $(n=1,0.007 \%)$.

Results revealed a strong heterogeneity $\left(I^{2}=99.56 \%\right.$; $P<0.001$ ) among the selected studies (Fig. 2). The subgroup analysis was performed (Table 5) and its results illustrated that the prevalence of $\mathrm{CE}$ was significantly higher in the North [9\%, 95\% CI: 4-18\%] and West [6\%, 95\% CI: 3-11\%] regions of Iran. It was significantly more prevalent in patients younger than 40 years of age [7\%, 95\% CI: 4-12\%] and was lower in urban dwellers [1\%, 95\% CI: 0-5\%]. There were statistically significant differences between the overall prevalence of $\mathrm{CE}$ in the subgroup that used the combination of serological, clinical and imaging diagnostic methods [7\%, 95\% CI: 5-9\%] and subgroup that used only serological techniques [4\%, 95\% CI: 3-6\%]. There were no significant differences in the prevalence of $C E$ in the subgroups with low and high quality $(P=0.48)$. Based on the results of Egger's regression test (Fig. 6) the publication bias among included studies could not be ignored $(P<0.0001)$.

\section{Discussion}

According to our knowledge, this is the third systematic review and meta-analysis about the prevalence of human echinococcosis in Iran. In the first study [2], Shafiei and colleagues evaluated the seroprevalence of human CE in Iran during the time period of 1985 to 2015. They assessed only articles which diagnosed the disease based on serological techniques and did not include other studies that used clinical, imaging, and pathological diagnostic methods. In the second study [9], Khalkhali et al., studied the prevalence of both animal and human hydatidosis in Iran (from January 1990 to December 2015), with the most focus on definitive and intermediate hosts. Both studies did not evaluate the situation of AE in Iran and distribution of infection in different parts of the body. Thus, we performed this study to have a more comprehensive assessment about echinococcosis in Iran.

The result of our study demonstrated that the estimated pooled prevalence of CE in Iran during a period of 27 years (from January 1990 to August 2017) was 5\% [95\% CI: 3-6\%]. This was the same as the rate reported by Shafiei et al., [5\%, 95\% CI: 4-6\%] [2] and similar to the rate of Khalkhali et al., [4.2\%, 95\% CI: 3-5.5\%] and was higher than the rate reported by $\mathrm{Li}$ et al., (3.2\%) from China [94] and Solomon et al., (3.8\%) from Kenya [95]. The differences in the prevalence of $\mathrm{CE}$ in various studies can be due to the differences in climatic conditions in each region, which could affect the viability of parasite's eggs, the frequency of infected final hosts and livestock farming in each region, level of contact with dogs, and occupation of the understudy population [46].

As mentioned before, the information about $\mathrm{AE}$ in Iran is so limited and there are few reports in this field. This is because that in contrast to the $\mathrm{CE}, \mathrm{AE}$ is a rare infection in Iran [76]. In the study conducted by Wacław et al., from Poland [96], 120 cases of AE-infected patients were reported during a 20 years study, suggesting that $\mathrm{AE}$ is an emerging infection in this country. . Although, AE is an uncommon infection in Iran, due to

Table 4 Sub- group analysis of the prevalence of cystic echinococcosis (CE) in different sites of body

\begin{tabular}{lllll}
\hline Site of cyst formation & Prevalence $(95 \% \mathrm{Cl})$ & $P^{2}(\%)$ & Heterogeneity $\left(X^{2}\right)$ & $P$ value \\
\hline Liver & $0.55(0.46-0.65)$ & 99.28 & 5169.09 & $<0.001$ \\
Lung & $0.28(0.22-0.35)$ & 98.41 & 2334.25 & $<.001$ \\
Spleen & $0.02(0.01-0.02)$ & 62.98 & 45.92 & $<.001$ \\
Kidney & $0.01(0.01-0.02)$ & 9.5 & 23.21 & 0.33 \\
Brain & $0.02(0.01-0.02)$ & 75.08 & 64.22 & $<0.001$ \\
Peritoneum & $0.01(0.00-0.02)$ & 52.25 & 23.03 & 0.02 \\
Pelvis & $0.01(0.00-0.01)$ & 42.24 & 17.3 & 0.07 \\
Gallbladder & $0.02(0.00-0.03)$ & 47.72 & 7.65 & 0.11 \\
Abdomen & $0.01(0.01-0.02)$ & 55.8 & 20.36 & 0.02 \\
Pancreas & $0.00(-0.00-0.00)$ & 2.57 & 7.18 & 0.41 \\
Unusual localized cyst & $0.02(0.01-0.03)$ & 73.39 & 75.16 & $<0.001$ \\
Multiple organ involvement & $0.1(0.07-0.12)$ & 91.96 & 298.39 & $<.001$ \\
\hline
\end{tabular}




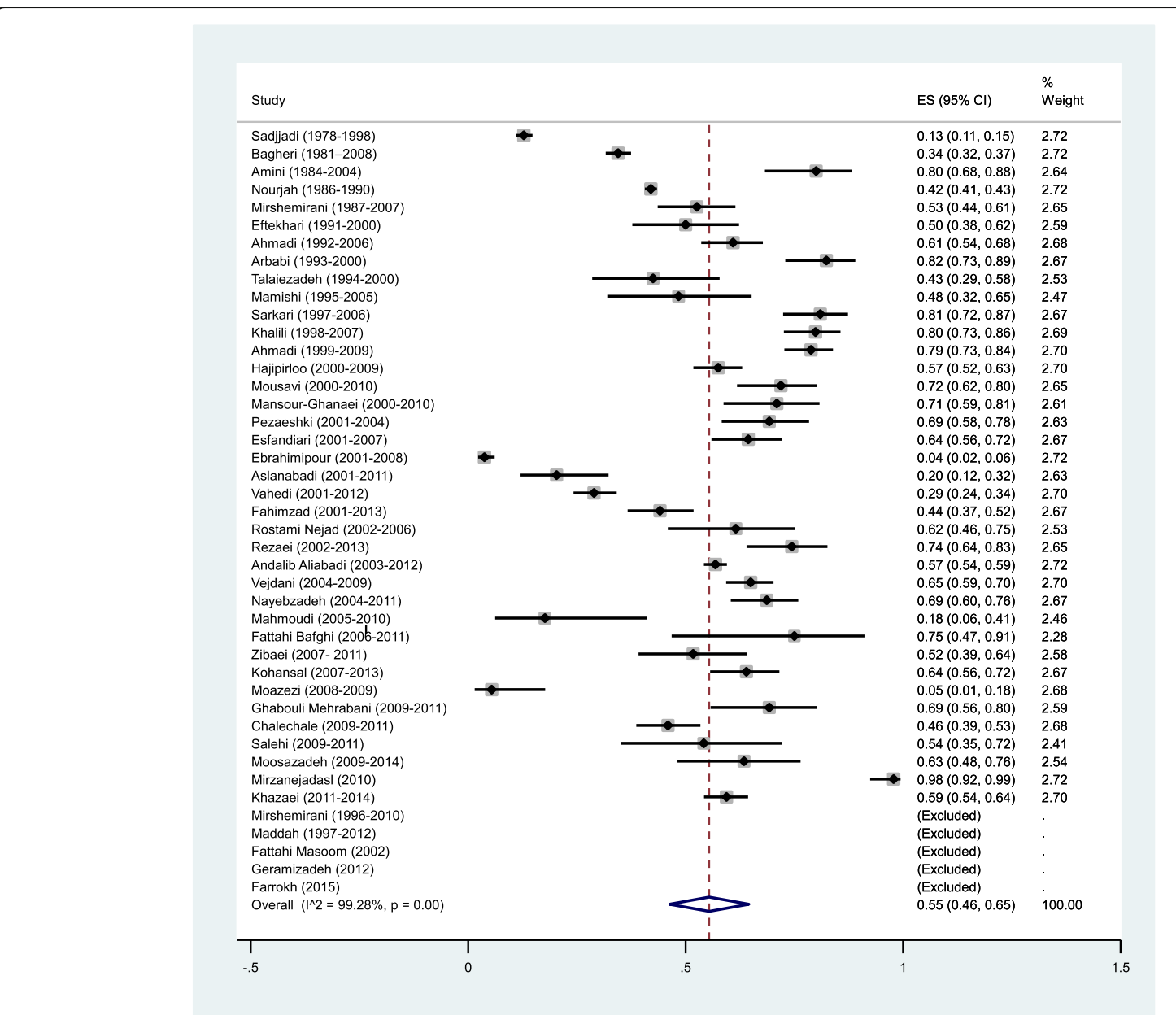

Fig. 4 Forest plot diagram of the total prevalence of hydatid cyst in liver. The middle point of each line indicates the prevalence rate and the length of line indicates $95 \%$ confidence interval of each study. The opened diamond is representatives of the overall prevalence of the studies

the high lethality of this disease, physicians should consider the possibility of AE in the differential diagnosis when dealing with patients that have extensive, infiltrating tumor-like lesions in the liver [97, 98].

Our investigations revealed that in adult group, the echinococcosis was more prevalent among women, especially housewives. A reversed result was reported by Conchedda et al., from Italy [99], which the patients' male to female ratio was 1.36. It seems that in some areas of Iran especially in villages, women have more contact with sources of infection (i.e. soil, dogs, and contaminated raw vegetables) than men $[46,62]$. They participate in farming and herding and have contact with domestic animals (intermediate hosts of E. granulosus) when feed them or clean their living space or when milking [24, 28, 43]. which is mostly common among pregnant women.

Assessment of organ distribution of cysts demonstrated that different organs were involved in CE (Tables 3 and 4), however, liver was the most affected organ [55\%, 95\% CI:
46-65\%]. This was in agreement with other studies [99101]. . This observation can be explained by the fact that the liver and lungs are the most important body filters and are the first sites to encounter the migrating parasite larvae, and usually a few parasites can escape from them and gain access to other organs [102].

The meta-analysis revealed that the prevalence of $\mathrm{CE}$ was higher in the North [9\%, 95\% CI: 4-18\%] and West [6\%, 95\% CI: 3-11\%] parts of Iran. The highest rate of $\mathrm{CE}$ was reported from Kermanshah (a western province of Iran) [55\%, 95\% CI: 51-60\%] and Mazandaran (a northern province of Iran) [32\%, 95\% CI: 28-36\%] and the lowest rate was related to Lorestan, Yazd, and Sistan and Baluchestan $(<1 \%)$. This was in contrast to the results of Shafiei et al., [2] and Khalkhali et al., [9] that the highest rates were related to the West and Southwest of Iran. A possible explanation for this controversy can be the different studies that were evaluated in the two other systematic reviews than our study. 


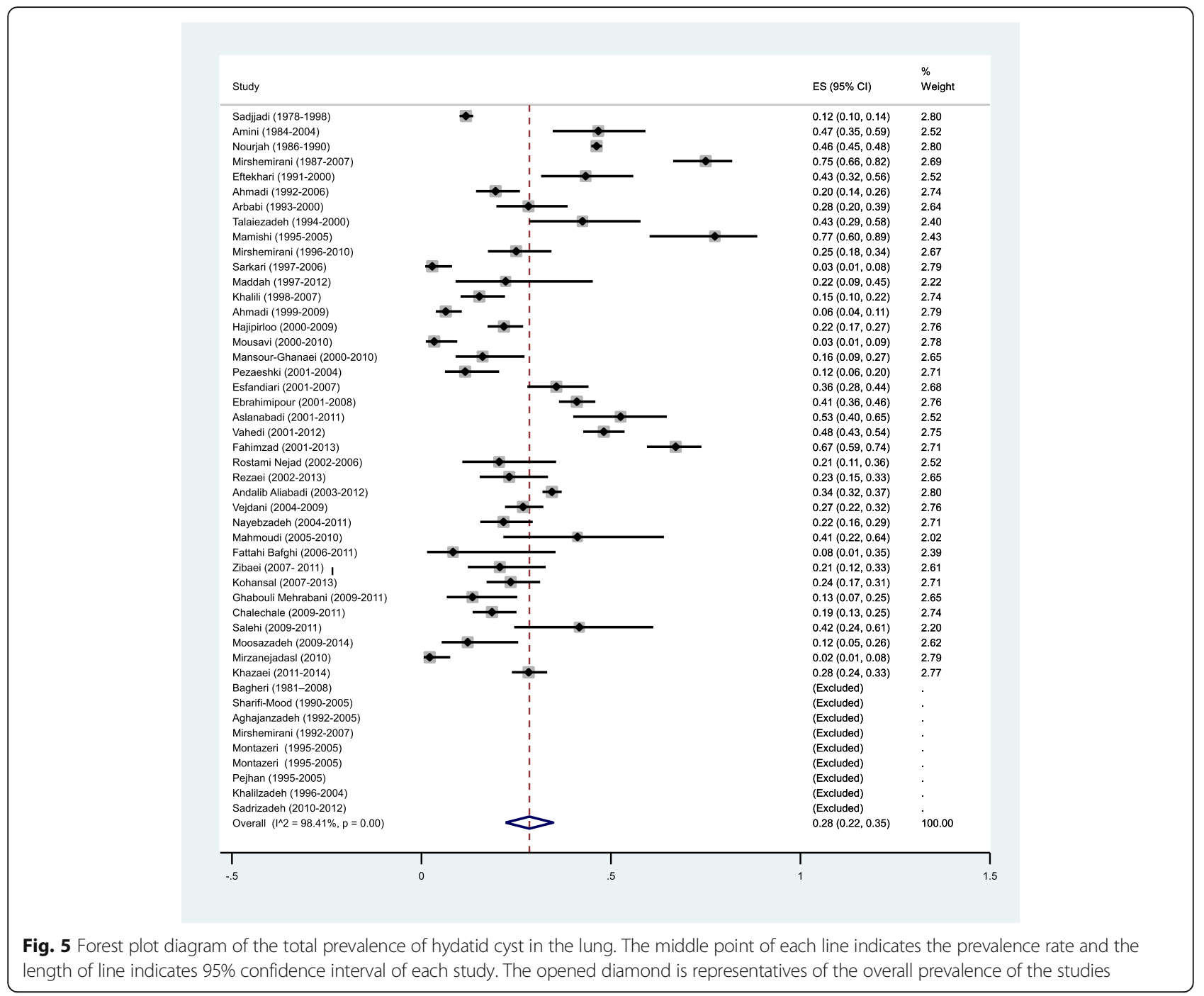

Our findings showed that patients in the age group of 20-40 years [7\%, 95\% CI: 4-12\%] were the main sufferers of CE. In other studies from Turkey [103] and Italy [99] CE was more prevalent among middle-aged and old patients. Since the 20-40 years people are among the most active age groups of the society, $\mathrm{CE}$ can have devastating economic damages [71, 81].

Our study revealed a higher CE prevalence rate among rural dwellers and nomads [6\%, 95\% CI: 2-12\%] than city residents [1\%, 95\% CI: $0-5 \%]$. Similar results were reported from other studies [100, 104, 105]. This is due to the lifestyle and occupation of villagers and nomads that result in their higher exposure to the infection sources [61]. Serological techniques $(n=27 / 77$, $35 \%)$ were the most frequently used methods for diagnosis of CE. However, higher rates of infection were detected by the combination of serological, clinical, and imaging methods [7\%, 95\% CI: 5-9\%] compared to the serologic methods alone [4\%, 95\% CI: 3-6\%).
Investigations revealed that the positivity of individuals with serological methods is not indicative of the definite involvement of a person in CE or the presence of active hydatid cysts in the body [29]. These techniques have some limitations; therefore, serodiagnostic tests should be used as complementary or confirmatory methods of $\mathrm{CE}$ detection and a combination of serologic, clinical, and imaging approaches is the most appropriate CE-diagnostic method.

There are some limitations to this study. First, most of the hospital-based retrospective studies reported the number of infected cases during a specific time interval, but did not report the prevalence rate of infection. Therefore, these studies did not include into the metaanalysis. This means that some of the potential useful studies were excluded and their data were not utilized. Second, there were limited data from some provinces of Iran such as Golestan, Ilam, Markazi, West Azerbaijan, Yazd, and Zanjan. 
Table 5 Sub-group meta-analysis of the prevalence of cystic echinococcosis (CE) in Iran

\begin{tabular}{|c|c|c|c|c|c|c|c|}
\hline \multicolumn{2}{|l|}{ Subgroup variable } & \multirow{2}{*}{$\begin{array}{l}\text { Prevalence }(95 \% \mathrm{Cl}) \\
0.09(0.04-0.18)\end{array}$} & \multirow{2}{*}{$\begin{array}{l}P^{2}(\%) \\
98.73\end{array}$} & \multirow{2}{*}{$\begin{array}{l}\text { Heterogeneity }\left(x^{2}\right) \\
315.38\end{array}$} & \multirow{2}{*}{$\begin{array}{l}P \text { value } \\
<0.001\end{array}$} & \multirow{2}{*}{$\frac{\text { Interaction test }\left(x^{2}\right)}{12.95}$} & \multirow{2}{*}{$\frac{P \text { value }}{<0.001}$} \\
\hline Geographical distribution & North & & & & & & \\
\hline & Center & $0.02(0.01-0.03)$ & 98.87 & 970.4 & $<0.001$ & & \\
\hline & West & $0.06(0.03-0.11)$ & 99.71 & 4477.29 & $<0.001$ & & \\
\hline & East & $0.05(0.01-0.11)$ & 96.4 & 83.22 & $<0.001$ & & \\
\hline \multirow[t]{3}{*}{ Age } & $<40$ years & $0.07(0.04-0.12)$ & 99.23 & 1937.99 & $<0.001$ & 40.03 & $<0.001$ \\
\hline & $\geq 40$ years & $0.05(0.03-0.06)$ & 95.24 & 230.86 & $<0.001$ & & \\
\hline & $N D^{a}$ & $0.01(0.00-0.01)$ & 98.8 & 465 & $<0.001$ & & \\
\hline \multirow[t]{2}{*}{ Quality score } & Low & $0.05(0.01-0.12)$ & 99.59 & 2426.9 & $<0.001$ & 0.49 & 0.48 \\
\hline & High & $0.04(0.03-0.06)$ & 99.56 & 5225.56 & $<0.001$ & & \\
\hline \multirow[t]{2}{*}{ Diagnostic lab method } & Serological & $0.04(0.03-0.06)$ & 98.22 & 1459.33 & $<0.001$ & 257.4 & $<0.001$ \\
\hline & Serological, clinical, and imaging ${ }^{b}$ & $0.07(0.05-0.09)$ & 79.06 & 14.33 & $<0.001$ & & \\
\hline \multirow[t]{4}{*}{ Place of residence } & Urban & $0.01(0.00-0.05)$ & 98.48 & 262.31 & $<0.001$ & 18.63 & $<0.001$ \\
\hline & Urban and rural & $0.06(0.03-0.1)$ & 99.57 & - & - & & \\
\hline & Rural and nomads & $0.06(0.02-0.12)$ & 98.13 & 214.1 & $<0.001$ & & \\
\hline & ND & $0.05(0.01-0.12)$ & 99.66 & 1191.6 & $<0.001$ & & \\
\hline All studies & & $0.05(0.00-0.16)$ & 99.56 & 7797.5 & $<0.001$ & - & - \\
\hline
\end{tabular}

a ND Not-determined

${ }^{\mathrm{b}}$ Clinical and imaging methods are included: clinical manifestations of the patients, in combination with the results of imaging and radiographic diagnostic methods (computed tomography (CT) scan, magnetic resonance imaging (MRI), chest-X ray, ultrasonography, bronchoscopy, or radiology) or pathological and histopathological examinations

\section{Conclusion}

In conclusion, given to the importance of echinococcosis on human health and domestic animals industry, it is necessary to implement monitoring and control measures in this regard. This requires public health education and awareness about the dangers of the disease and its transmission and preventive routes, education on the appropriate ways of washing and disinfecting of vegetables and fruits, education on the correct ways of animal slaughtering, prevention on feeding dogs by viscera of home-slaughtered animals, prevention on direct contact by dogs' feces, enforce legislation on meat inspection and improve veterinary services, fighting stray dogs, treating and vaccination of dogs and domestic animals, investigation on the pollution of water and soil resources in endemic areas such as the North and West of Iran in terms of Echinococcosis' eggs.

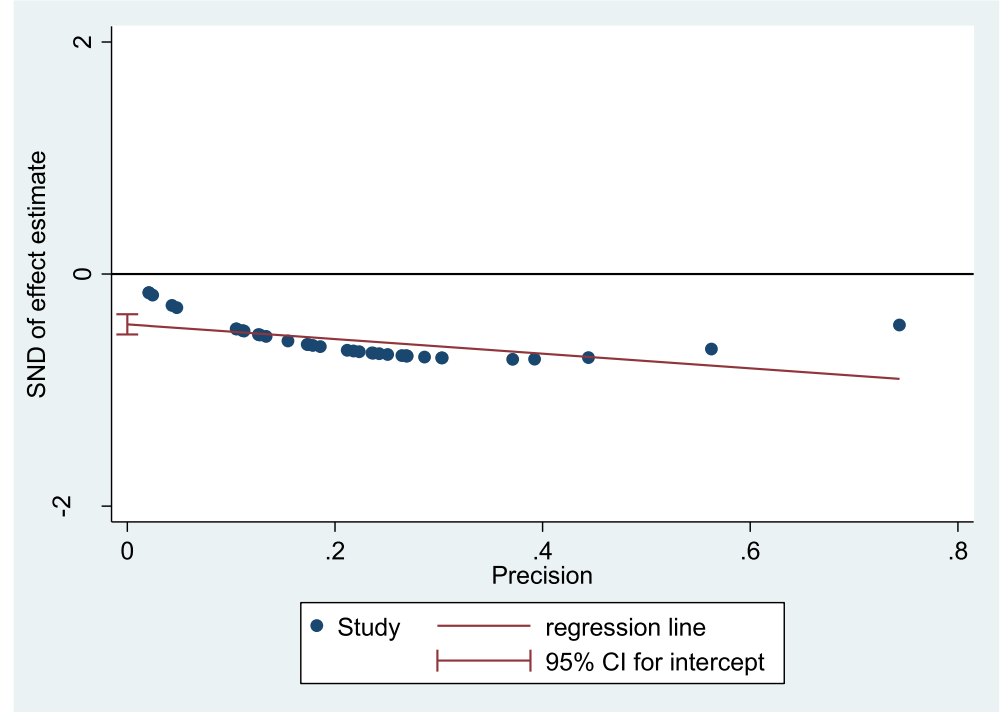

Fig. 6 The Egger's test graph to test for publication bias $(P$ value $<0.0001)$ 


\section{Abbreviations}

AE: Alveolar echinococcosis; CE: Cystic echinococcosis;

CIE: Counterimmunoelectrophoresis; CT: Computed tomography scan; ELISA: Enzyme-linked immunosorbent assay; IFA: Indirect fluorescent antibody test; IHA: Indirect hemagglutination antibody test; MRI: Magnetic resonance imaging; WHO: World Health Organization

\section{Acknowledgements}

Not Applicable

\section{Authors' contributions}

$\mathrm{SM}, \mathrm{MB}$ and $\mathrm{BP}$ were involved in the study design and data collection and had full access to all of the data in the study and take responsibility for the integrity of the data and the accuracy of the data analysis. MB and SM wrote the initial draft of the manuscript. BP, SM, HK and SM were involved in data analysis and interpretation, reviewing the manuscript and providing critical feedback and assessment. All authors have seen and approved the final version of the manuscript.

\section{Funding}

The design of the study and collection, analysis, and interpretation of data was supported by a grant (grant number: 97-01-88-36715) from Tehran University of Medical Sciences to Dr. Shima Mahmoudi.

\section{Availability of data and materials}

All data obtained

\section{Ethics approval and consent to participate}

Not applicable.

\section{Consent for publication}

Not applicable

\section{Competing interests}

The authors declare that they have no competing interests.

\section{Author details}

'Pediatric Infectious Disease Research Center, Tehran University of Medical Sciences, Tehran, Iran. ${ }^{2}$ Center for Research of Endemic Parasites of Iran (CREPI), Tehran University of Medical Sciences, Tehran, Iran. ${ }^{3}$ Department of Medical Parasitology and Mycology, School of Public Heath, Tehran University of Medical Sciences, Poursina st, P.O. Box 14155-6446, Tehran, Iran.

Received: 24 December 2018 Accepted: 10 September 2019

\section{Published online: 04 November 2019}

\section{References}

1. Rokni M. Echinococcosis/hydatidosis in Iran. Iran J Parasitol. 2009;4(2):1-16.

2. Shafiei R, Teshnizi SH, Kalantar K, Gholami M, Mirzaee G, Mirzaee F. The Seroprevalence of Human Cystic Echinococcosis in Iran: A Systematic Review and Meta-Analysis Study.J. Parasitol Res. 2016;2016:1425147.

3. Aghajanzadeh M, Safarpoor F, Amani H, Alavi A. One-stage procedure for lung and liver hydatid cysts. Asian Cardiovasc Thorac Ann. 2008;16(5):392-5.

4. McManus DP, Zhang W, Li J, Bartley PB. Echinococcosis. Lancet. 2003; 362(9392):1295-304

5. Moro P, Schantz PM. Echinococcosis: a review. Int J Infect Dis. 2009; 13(2):125-33

6. World Health Organization (WHO). Charateristics and details of echinococcosis. http://www.who.int/mediacentre/factsheets/fs377/en/.

7. Ito A, Budke CM. The echinococcoses in Asia: The present situation. Acta Trop. 2017;176:11-21.

8. Eckert J, Deplazes P. Biological, epidemiological, and clinical aspects of echinococcosis, a zoonosis of increasing concern. Clin Microbiol Rev. 2004;17(1):107-35.

9. Khalkhali H, Foroutan M, Khademvatan S, Majidiani H, Aryamand S, Khezri P, et al. Prevalence of cystic echinococcosis in Iran: a systematic review and meta-analysis. J Helminthol. 2018:92(3):260-68.

10. Khademvatan S, Majidiani H, Foroutan M, Tappeh KH, Aryamand S, Khalkhali H. Echinococcus granulosus genotypes in Iran: a systematic review. J Helminthol. 2019;93(2):131-8.
11. Siyadatpanah A, Anvari D, Emami Zeydi A, Hosseini SA, Daryani A, Sarvi S, et al. A systematic review and meta-analysis for genetic characterization of human echinococcosis in Iran, an endemic country. Epidemiol Health. 2019; 41:2019024.

12. Nejad MR, Mojarad EN, Norouzina M, Harandi MF. Echinococcosis: based on molecular studies in Iran. Gastroenterol Hepatol Bed Bench. 2010; 3(4):169-76.

13. Harandi MF, Budke CM, Rostami S. The monetary burden of cystic echinococcosis in Iran. PLoS Negl Trop Dis. 2012;6(11):e1915.

14. Liberati A, Altman DG, Tetzlaff J, Mulrow C, Gøtzsche PC, loannidis JP, et al The PRISMA statement for reporting systematic reviews and meta-analyses of studies that evaluate health care interventions: explanation and elaboration. PLoS Med. 2009:6(7):1000100.

15. Smego RA Jr, Bhatti S, Khaliq AA, Beg MA. Percutaneous aspirationinjection-reaspiration drainage plus albendazole or mebendazole for hepatic cystic echinococcosis: a meta-analysis. Clin Infect Dis. 2003;37(8):1073-83.

16. JB I. Joanna Briggs Institute Reviewers' Manual: 2014 edition/Supplement Australia: The Joanna Briggs Institute, The University of Adelaide; 2014

17. Begg CB, Mazumdar M. Operating characteristics of a rank correlation test for publication bias. Biometrics. 1994;50:1088-101.

18. Statistical Center of Iran. Iran statistical yearbook. https://www.amar.org.ir/ english/Iran-Statistical-Yearbook.

19. Statistical Center of Iran. Population and Housing Censuses. https://www.amar. org.ir/english/Population-and-Housing-Censuses/Census-2016-General-Results.

20. Aslanabadi S, Zarrintan S, Abdoli-Oskouei S, Salehpour F, Zarrintan A, Beheshtirouy $\mathrm{S}$, et al. Hydatid cyst in children: A 10-year experience from Iran. AJPS. 2013;10(2):140-4.

21. MirzanejadasI H, Fasihi Harandi M, Deplazes P. Serological survey of human cystic echinococcosis with ELISA method and CHF Ag. Iran Res J Biol Sci. 2008:3(1):64-7.

22. Mirzanejad-As H, Ghoreishi M, Ghahramani A, Mehmandar W, Mirzanejad-As $\mathrm{H}$. Serological and sonographical survey of hydatid disease in Moghan Plain of Iran. RJMS. 2010;4(2):75-80.

23. Heidari Z, Mohebali M, Zarei Z, Aryayipour M, Eshraghian M, Kia E, et al. Seroepidemiological study of human hydatidosis in meshkinshahr district, ardabil province, iran. Iran J Parasitol. 2011;6(3):19-25.

24. Khalili B, Shahrani M, Moradi M. Study of hydatid cyst in hospitalized patients with operation in Chaharmahal va Bakhtiary province. J Shahrekord Univ Med Sci. 2007;12(1):69-74

25. Darani HY, Avijgan M, Karimi K, Manouchehri K, Masood J. Seroepidemiology of hydatid cyst in Chaharmahal va Bakhtiari Province, Iran. Iran J Public Health. 2003;32(2):31-3.

26. Montazeri V, Sokouti M, Rashidi MR. Comparison of pulmonary hydatid disease between children and adults. Tanaffos. 2007;6(1):13-8.

27. Vahedi MA, Vahedi ML. Demographics of patients with surgical and nonsurgical cystic echinococcosis in East Azerbaijan from 2001 to 2012. PJBS. 2012;15(4):186-91.

28. Ghabouli Mehrabani N, Kousha A, Khalili M, Mahami Oskouei M, Mohammadzadeh M, Alizadeh S, Maleksabet A, et al. Hydatid cyst surgeries in patients referred to hospitals in East Azerbaijan province during 20092011. Iran J Parasitol. 2014;9(2):233-8.

29. Garedaghi Y, Bahavarnia SR. Seroepidemiology of human hydatidosis by ELISA method in east-azarbaijan province in Iran in year 2009. IRJE. 2011;7(2):25-9.

30. Dadkhah MA, Yeganehzad M, Nadery B. Survey on Hydatid Cyst Infestation in Sarab City (Northwest of Iran) Using Epidemiological and Seroepidemiological Criteria. JAVA. 2011;10(16):2099-101.

31. Sadjjadi S, Ardehali S, Noman Pour B, Kumar V, Izadpanah A. Diagnosis of cystic echinococcosis: ultrasound imaging or countercurrent immunoelectrophoresis? 2001

32. Saberi-Firouzi M, Kaffashian F, Hayati E, Ghaderi A, Keshavarz H, Arshadi S, et al. Prevalence of hydatidosis in nomadic tribes of southern Iran. MJIRI. 1998;12(2):113-8.

33. Kavous S, Kazemi A, Jelodari S. Seroepidemiology of human hydatid cyst in jahrom. J Jahrom Univ Med Sci. 2010;8(3):18-24.

34. Sarkari B, Hosseini F, Abdolahi Khabisi S, Sedaghat F. Seroprevalence of cystic echinococcosis in blood donors in Fars province, southern Iran. Parasite Epidemiol Control. 2017;2(1):8-12.

35. Mansour-Ghanaei F, Joukar F, Soati F, Javadi M. Clinical features of hydatid disease in Guilan (the north province of iran): A ten-year study. Arch Clin Infect Dis. 2012;7(4):119-23. 
36. Baharsefat M, Massoud J, Mobedi I, Farahnak A, Rokni M. Seroepidemiology of human hydatidosis in Golestan province, Iran. Iran J parasitol. 2007;2(2):20-4.

37. Ahmadi NA, Hamidi M. A retrospective analysis of human cystic echinococcosis in Hamedan province, an endemic region of Iran. Ann Trop Med Parasitol. 2008;102(7):603-9.

38. Ahmadi NA, Hamidi M. Unusual localizations of human hydatid disease in Hamedan province, west of Iran. Helminthologia. 2010;47(2):94-8.

39. Aflaki A, Ghaffarifar F, Dalimi AH. Seroepidemiological survey of human hydatidosis using Dot-ELISA in llam Province (Western part of Iran); 2005.

40. Arbabi M, Hooshyar H. Survey of echinococcosis and hydatidosis in Kashan region, central Iran. Iran J Public Health. 2006;35(1):75-81.

41. Fahimzad A, Karimi A, Tabatabaei SR, Armin S, Ghanaei RM, Fallah F, et al. Overview of hydatid disease in iranian children. Arch Pediatr Infect Dis. 2015;3(3):e30084

42. Eftekhari F. Clinical and demographic features of patients with Hydatid cyst admitted in Kerman University hospitals between 1991-2000. JKMU. 2005;12(4):252-7.

43. Harandi MF, Moazezi SS, Saba M, Grimm F, Kamyabi H, Sheikhzadeh F, et al. Sonographical and serological survey of human cystic echinococcosis and analysis of risk factors associated with seroconversion in rural communities of Kerman, Iran. Zoonoses Public Health. 2011;58(8):582-8.

44. Moazezi SS, Saba M, Kamyabi H, SHikhzadeh F. Sonographic and serological survey of hydatid disease in Rural regions of Shahdad and chatroud Kerman province, 2006-2007. JKMU. 2009;15(1):25-34.

45. Vejdani M, Vejdani S, Lotfi S, Najafi F, Nazari N, Hamzavi Y. Study of operated primary and secondary (recurrence) hydatidosis in hospitals of Kermanshah, west of Islamic Republic of Iran. East Mediterr Health J. 2013;19(7):671-5.

46. Chalechale A, Hashemnia M, Rezaei F, Sayadpour M. Echinococcus granulosus in humans associated with disease incidence in domestic animals in Kermanshah, west of Iran. J Parasit Dis. 2016;40(4):1322-9.

47. Bagheri R, Haghi SZ, Amini M, Fattahi AS. Pulmonary Hydatid cyst: Analysis of 1024 cases. TUMS. 2010;68(3):188-93.

48. Ebrahimipour M, Budke CM, Najjari M, Yaghoobi K. Surgically managed human cystic echinococcosis in north-eastern Iran: a single center's experience from 2001 to 2008. J Parasit Dis. 2017;41(3):883-87.

49. Aliabadi ZA, Berenji F, Abdolmajid F, Jarahi L. Human Hydatidosis/ Echinococosis in North Eastern Iran from 2003-2012. Iran J Parasitol. 2015;10(4):658.

50. Sadrizadeh A, Haghi S, Masuom SH, Bagheri R, Dalouee M. Evaluation of the effect of pulmonary hydatid cyst location on the surgical technique approaches. Lung India. 2014;31(4):361-5.

51. Khazaei S, Rezaeian S, Khazaei Z, Goodarzi E, Khazaei S, Mohammadian $M$, et al. Epidemiological and Clinical Characteristics of Patients with Hydatid Cysts in Khorasan Razavi Province, from 2011 to 2014. Iran J Parasitol. 2016;11(3):364-70.

52. Fotoohi S, Hashemi Tabar GR, Borji H. Serodiagnosis of human hydatidosis with an ELISA developed based on antigens derived from sheep hydatid cysts and comparison with a commercial human ELISA kit. Asian Pac J Trop Med. 2013;6(9):723-7.

53. Talaiezadeh AH, Maraghi S. Hydatid disease in children: A different pattern than adults. Pak J Med Sci. 2006;22(3):329-32.

54. Rafiei A, Hemadi A, Maraghi S, Kaikhaei B, Craig PS. Human cystic echinococcosis in nomads of south-west Islamic Republic of Iran. East Mediterr Health J. 2007;13(1):41-8.

55. Sarkari B, Naghmachi M, Azimi S, Vaezi M, Ebrahimi S. Human cystic echinococcosis in Yasuj: A survey of ten year hospital records. Armaghane danesh. 2007;12(3):127-34

56. Sarkari B, Sadjjadi SM, Beheshtian MM, Aghaee M, Sedaghat F. Human cystic echinococcosis in Yasuj District in Southwest of Iran: an epidemiological study of seroprevalence and surgical cases over a ten-year period. Zoonoses Public Health. 2010;57(2):146-50.

57. Akhlaghi L, Massoud J, Housaini A. Observation on hydatid cyst infection in Kordestan Province (West of Iran) using epidemiological and seroepidemiological criteria. Iran J Public Health. 2005;34(4):73-5.

58. Hadadian M, Ghaffarifar F, Dalimiasl A, Roudbar MS. Seroepidemiological survey of hydatid cyst by ELISA in Kordestan province; 2008.

59. Nejad MR, Hoseinkhan N, Nazemalhosseini E, Cheraghipour K, Abdinia E, Zali MR. An analysis of hydatid cyst surgeries in patients referred to hospitals in Khorram-Abad, Lorestan during 2002-06. Iran J Parasitol. 2007;2(3):29-33.
60. Nayebzadeh H, Tarrahi MJ, Arian A, Nayebaghaee SM. Epidemiological Study of Human Operated Hydatid Cysts during 2004-2011 in Lorestan Province. J Zoonoses Res. 2014;1(2):37-40.

61. Zibaei M, Azargoon A, Ataie-Khorasgani M, Ghanadi K, Sadjjadi SM. The serological study of cystic echinococcosis and assessment of surgical cases during 5 years (2007-2011) in Khorram Abad, Iran. Niger J Clin Pract. 2013: 16(2):221-5.

62. Asgari M, Mohebali M, Kia EB, Farahnak A, Aryaeipour M, Asadian S, et al. Seroepidemiology of human hydatidosis using AgB-ELISA test in Arak, central Iran. Iran J Public Health. 2013;42(4):391-6.

63. Esfandian B, Youssefi MR, Ziapour SP, Fard SH, Abouhosseini M, Espeh-Kolaie MA. Evaluation of hydatid cyst surgeries in Northern Iran (Mazandaran Province) during 2001-2007. JAMA. 2010;9(7):1128-30.

64. Moosazadeh M, Abedi G, Mahdavi SA, Shojaee J, Charkame A, Afshari M. Epidemiological and clinical aspects of patients with hydatid cyst in Iran. J Parasit Dis. 2017:41(2):356-60.

65. Ziaei Hezarjaribi H, Fakhar M, Rahimi Esboei B, Soosaraei M, Ghorbani A, Nabyan N, et al. Serological evidence of human cystic echinococcosis and associated risk factors among general population in Mazandaran Province, northern Iran. Ann Med Surg. 2017;18:1-5.

66. Salehi M, Adinezade A, Khodajo R, Saberi Z, Yousefi A. The epidemiologic survey of operated patients with hydatid cyst in hospitals of North Khorasan province during 2010-2011. J North Khorasan Univ Med Sci. 2013;4(4):623-9.

67. Rezaei F, Saghafipour A, Sheikholeslami NZ, Jooshi MK. Investigation of Demographic and Clinical Status of Sufferers of Hydatid Cysts Referred to Hospitals Affiliated to Qom University of Medical Sciences during a 12-Year Period (2002-2013), Iran. Qom Univ Med Sci J. 2014;8(5).

68. Rakhshanpour A, Fasihi Harandi M, Moazezi SS, Rahimi MT, Mohebali M, Mowlavi GH, et al. Seroprevalence of human hydatidosis using ELISA method in Qom province, central Iran. Iran J Parasitol. 2012;7(3):10-5.

69. Sharifi-Mood B, Fazaeli A, Izadi S, Mokhtari S. Fifteen years experience with pulmonary hydatidosis in Zahedan, Iran. Iran J parasitol. 2007;2(4):7-11.

70. Moradi H, Maroufi Y, Dabirzadeh M. Seroepidemiology of Human Hydatid Cyst in Shahrebabk Using ELISA. JMUM. 2016;25(133):315-8.

71. Amini M, Bahador M, Malekhoseyni M. Evaluation of hydatid cyst manifestations in patients admitted to Shaheed Modarres Hospital, 19842004. Arch Clin Infect Dis. 2008;2(4):177-80.

72. Nourjah N, Sahba G, Baniardalani M, Chavshin A. Study of 4850 operated hydatidosis cases in Iran. Southeast Asian J Trop Med Public Health. 2004;35:218-22.

73. Mirshemirani A, Pourang H, Rouzrokh M, Sadeghian N, Kouranlou J, Molaeian M. Clinical appearance of hydatid cyst in four pediatric surgical centers of Tehran; 2008. p. 36-43.

74. Mirshemirani AR, Razavi S, Sadeghian S. Surgical treatment of pulmonary hydatid cyst in 72 children. Tanaffos. 2009:8(1):56-61.

75. Pejhan S, Zadeh MRL, Javaherzadeh M, Shadmehr MB, Arab M, Kakhki AD, et al. Surgical treatment of complicated pulmonary hydatid cyst. Tanaffos. 2007:6(1):19-22.

76. Mamishi S, Sagheb S, Pourakbari B. Hydatid disease in Iranian children. J Microbiol Immunol Infect. 2007;40(5):428-31.

77. Khalilzadeh S, Baghaie N, Ghafarzadeh B, Shadmehr MB, Velayati AA Hydatid pulmonary disease in children: a nine-year study. Tanaffos. 2004;3(12):43-8

78. Mirshemirani A, Khaleghnejad A, Kouranloo J, Sadeghian N, Rouzrokh M, Hasas-Yeganeh S. Liver hydatid cyst in children (A 14-year review). Iran J Pediatr. 2011;21(3):385-9.

79. Sedaghat GH, Massoud J, Rokni M, Kia E. Seroepidemiologic study of human Hydatidosis in Shahriar area, south of Tehran in 1999. J kerman Univ Med Sci. 2001:8(1):44-49.

80. Ahmadi NA, Badi F. Diagnostic, surgical, and medicinal approaches of human cystic echinococcosis: A review of 203 cases in Tehran, Iran. Infect Dis Clin Prac. 2012;20(6):390-3.

81. Mousavi SR, Samsami M, Fallah M, Zirakzadeh H. A retrospective survey of human hydatidosis based on hospital records during the period of 10 years. J Parasit Dis. 2012;36(1):7-9.

82. Pezeshki A, Kia EB, Gholizadeh A, Koohzare A. An analysis of hydatid cyst surgeries in Tehran Milad Hospital, Iran during 2001-2004. Pak J Med Sci. 2007;23(1):138-40

83. Mahmoudi S, Elikaee S, Keshavarz H, Pourakbari B, Mamishi S. Pediatric hydatidosis in Iranian referral pediatrics center. Iran J Parasitol. 2012;7(2):87-91. 
84. G. L. B, Farrokhzad MN, Poya MRN. Investigation of the prevalence of hydatid cysts in rural areas shemiranat of Tehran and reviews of IFA test. Research in Medicine. 2004;30(30):241-4.

85. Tavalla M, Akhlaghi L, Ourmazdi H, Sarvi S, Razmjoo E, Shokrabi M, et al. Using Dot-ELISA method to study the prevalence of human hydatidosis in people referred to blood transfusion center in Tehran, 2005-2006. RJMS. 2010;16(67):52-8.

86. Zariffard M, Abshar N, Akhavizadegan M, Motamedi G. Seroepidemiological survey of human hydatidosis in western parts of Iran. Arch Razi Inst. 1999;50:71-5.

87. Hajipirloo HM, Bozorgomid A, Alinia T, Tappeh Kh H, Mahmodlou R. Human cystic echinococcosis in west azerbaijan, northwest iran: a retrospective hospital based survey from 2000 to 2009. Iran J Parasitol. 2013;8(2):323-6.

88. Fattahi Bafghi A, Ghafourzadeh M, et al. IJML. 2015;2(2):128-33.

89. Kohansal MH, Nourian A, Bafandeh S. Human Cystic Echinococcosis in Zanjan Area, Northwest Iran: A Retrospective Hospital Based Survey between 2007 and 2013. Iran J Public Health. 2015;44(9):1277-82.

90. Maddah G, Abdollahi A, Sharifi-Nooghabi R, Tavassoli A, RajabiMashadi MT, Jabbari-Nooghabi A, et al. Difficulties in the diagnosis and management of alveolar hydatid disease: A case series. Caspian J Intern Med. 2016;7(1):52-6.

91. Esmaeili N, Arbabi M. Seroepidemiology of hydatidosis among adult human at Kashan region, Iran in 2008. Feyz. 2010;13(4):321-36.

92. Ilbeigi P, Mohebali M, Eshrat Beigom K, Saber-Inasab M, ARYAEIPOUR M, Bizhani N, et al. Seroepidemiology of Human Hydatidosis Using AgB-ELISA Test in Isfahan City and Suburb Areas, Isfahan Province, Central Iran. Iran J Public Health. 2015;44(9):1219.

93. Arbabi M, Masoud J, Asl AD, Sajadi M. Seroepidemiologic prevalence of Hydatid cyst in Hamadan 1991. Feyz. 1998;2(2):43-50.

94. Li T, Chen X, Zhen R, Qiu J, Qiu D, Xiao N, et al. Widespread co-endemicity of human cystic and alveolar echinococcosis on the eastern Tibetan Plateau, northwest Sichuan/southeast Qinghai, China. Acta trop. 2010;113(3):248-56.

95. Solomon N, Zeyhle E, Carter J, Wachira J, Mengiste A, Romig T, et al. Cystic Echinococcosis in Turkana, Kenya: The Role of Cross-Sectional Screening Surveys in Assessing the Prevalence of Human Infection. Am J Trop Med Hyg. 2017;97(2):587-95.

96. Nahorski WL, Knap JP, Pawłowski ZS, Krawczyk M, Polański J, Stefaniak J, et al. Human alveolar echinococcosis in Poland: 1990-2011. PLoS Negl Trop Dis. 2013;7(1):e1986.

97. Farrokh D, Zandi B, Pezeshki Rad M, Tavakoli M. Hepatic alveolar echinococcosis. Arch Iran Med. 2015;18(3):199-202.

98. Geramizadeh B, Baghernezhad M. Hepatic Alveolar Hydatid Cyst: A Brief Review of Published Cases from Iran in the Last 20 Years. Hepatitis Monthly. 2016;16(10):e58744.

99. Conchedda M, Antonelli A, Caddori A, Gabriele F. A retrospective analysis of human cystic echinococcosis in Sardinia (Italy), an endemic Mediterranean region, from 2001 to 2005. Parasitol Int. 2010;59(3):454-9.

100. Al-Qaoud KM, Craig PS, Abdel-Hafez SK. Retrospective surgical incidence and case distribution of cystic echinococcosis in Jordan between 1994 and 2000. Acta trop. 2003;87(2):207-14.

101. Torgerson P, Karaeva R, Corkeri N, Abdyjaparov T, Kuttubaev O, Shaikenov B. Human cystic echinococcosis in Kyrgystan: an epidemiological study. Acta trop. 2003;85(1):51-61.

102. Ahmadi NA, Badi F. Human hydatidosis in Tehran, Iran: a retrospective epidemiological study of surgical cases between 1999 and 2009 at two university medical centers. Trop Biomed. 2011;28(2):450-6.

103. Akalin S, Kutlu SS, Caylak SD, Onal O, Kaya S, Bozkurt Al. Seroprevalence of human cystic echinococcosis and risk factors in animal breeders in rural communities in Denizli, Turkey. J Infect Dev Ctries. 2014;8(09):1188-94.

104. Pierangeli NB, Soriano SV, Roccia I, Giménez J, Lazzarini LE, Grenóvero MS, et al. Heterogeneous distribution of human cystic echinococcosis after a long-term control program in Neuquén, Patagonia Argentina. Parasitol Int. 2007:56(2):149-55.

105. Saeed I, Kapel C, Saida L, Willingham L, Nansen P. Epidemiology of Echinococcus granulosus in Arbil province, northern Iraq, 1990-1998. J Helminthol. 2000;74(1):83-8.

\section{Publisher's Note}

Springer Nature remains neutral with regard to jurisdictional claims in published maps and institutional affiliations.

\section{Ready to submit your research? Choose BMC and benefit from}

- fast, convenient online submission

- thorough peer review by experienced researchers in your field

- rapid publication on acceptance

- support for research data, including large and complex data types

- gold Open Access which fosters wider collaboration and increased citations

- maximum visibility for your research: over $100 \mathrm{M}$ website views per year

At BMC, research is always in progress.

Learn more biomedcentral.com/submissions 